\title{
A validation study of loci associated with mastitis resistance in two French dairy sheep breeds
}

\author{
Claire Oget ${ }^{1 *} \mathbb{B}$, Charlotte Allain ${ }^{1}$, David Portes ${ }^{2}$, Gilles Foucras ${ }^{3}$, Alessandra Stella ${ }^{4}$, Jean-Michel Astruc ${ }^{5}$, \\ Julien Sarry', Gwenola Tosser-Klopp ${ }^{1 \dagger}$ and Rachel Rupp ${ }^{1+}$
}

\begin{abstract}
Background: The identification of loci associated with resistance to mastitis or of the causative mutations may be helpful in breeding programs for dairy sheep as it is for cattle worldwide. Seven genomic regions that control milk somatic cell counts, an indirect indicator of udder infection, have already been identified in sheep (Spanish Churra, French Lacaune and Italian Sardinian-Lacaune backcross populations). In this study, we used a 960 custom-designed ovine single nucleotide polymorphism (SNP) chip in Lacaune and Manech Tête Rousse dairy sheep to validate these seven genomic regions associated with mastitis.
\end{abstract}

Results: The most significant SNP (rs868996547) on Ovis aries chromosome (OAR) 3 was a previously described mutation in the suppressor of cytokine signalling 2 (SOCS2) gene. An antagonist effect of this causal candidate between health and growth in Lacaune sheep was confirmed. Effects of the mutation on the infectious status of the udder, i.e. increases in milk somatic cell counts and bacteria shedding, were also identified. This SNP was not present in the data available on Manech Tête Rousse. Three other regions associated with mastitis were also confirmed on OAR16 (Manech Tête Rousse), 19 (Lacaune) and 2 (both breeds). For the OAR2 region, we validated previously detected SNPs in several other breeds (Sarda, Churra, and Chios). For significant SNPs in the four mastitis regions, the effect varied from 0.24 to 0.67 phenotypic standard deviation of the traits. Two of the mastitis quantitative trait loci (QTL) regions (OAR2 and 16) that we validated here were also associated in opposite ways with milk production traits in both populations.

Conclusions: These results indicate, at least in part, a genomic basis for the trade-off between milk production and mastitis resistance. Four of the seven mastitis QTL regions that were previously identified in independent populations, were confirmed in this study, which demonstrates partial sharing of mastitis-related genetic mechanisms between different distant dairy sheep populations.

\section{Background}

Mastitis is an inflammation of the mammary gland, which in dairy sheep is mostly due to bacterial infections by Staphylococci [1]. Mastitis is a serious burden for the milk industry due to the altered quality of milk and increased cost of flock renewal. Beside hygienic measures, genetic selection for improved resistance to mastitis

\footnotetext{
*Correspondence: claire.oget@inra.fr

${ }^{\dagger}$ Gwenola Tosser-Klopp and Rachel Rupp contributed equally to this work ${ }^{1}$ GenPhySE, Université de Toulouse, INRA, ENVT, Castanet-Tolosan, France Full list of author information is available at the end of the article
}

is now implemented in breeding programs for several breeds of dairy ruminants worldwide [2]. However, its application to dairy sheep is still rare, mainly because the recording cost per animal, relative to potential income, is prohibitive for many traits other than production traits. In sheep, the identification of loci that are associated with resistance to udder infection or the causative mutations may be helpful in selection. However, resistance to mastitis is highly complex and the genetically determined biological basis behind this trait remains unknown.

Several quantitative trait loci (QTL) regions that control milk somatic cell count (SCC), an indirect indicator 
of udder infection, have been identified in dairy sheep through the EU-funded 3SR project (Sustainable solutions for small ruminants, FP7-KBBE-245140) [3]. For one of these QTL, Rupp et al. [4] identified a single nucleotide polymorphism (SNP) in the coding frame of the suppressor of cytokine signalling 2 (SOCS2) gene as the putative causal mutation associated with high SCC in the Lacaune breed. A few QTL regions were then confirmed by Banos et al. [5] in a population of the Greek Chios breed using four mastitis indicator traits, namely clinical mastitis occurrence, milk SCC, total viable bacterial count in milk and the California mastitis test.

The objective of our study was to confirm the ovine QTL that control mastitis resistance in two independent dairy sheep populations, using a 960 custom-designed ovine SNP chip.

\section{Methods}

Two independent French dairy sheep populations were used: Lacaune ewes $(\mathrm{N}=504)$ from a divergent selection based on extreme breeding values for SCC at the experimental facility of La Fage (INRA, UE 321, Roquefort, France) [6], and Manech Tête Rousse rams ( $=145)$ raised in the CDEO (Ordiarp, France) testing station in 2013 (birth year from 2008 to 2011). Among the 504 Lacaune individuals, 213 ewes belonged to the high SCC line $(42.2 \%)$ and 291 to the low SCC line $(57.7 \%)$. The selection lines were about three genetic standard deviations (SD) apart [6].

In the Lacaune ewe population, milk yield, fat content, protein content, and SCC were measured monthly at morning milking. Test-day SCC were log-transformed for normality into SCS [7]. The arithmetic averages of the first lactation test-days were then computed and corrected for year of sampling for fat content (FAT_L1), protein content (PROTEIN_L1), and SCS (LSCS_L1). The milk yield (MILK_L1) trait was computed as the trait used for genetic evaluation, i.e. the 250-day cumulative production adjusted for lactation length and standardized to an adult production $(\times 1.3)$. MILK_L1 was multiplied by 1.3 to follow the definition used in the Manech Tête Rousse breed for genetic evaluation and allow direct comparison of average milk production between both breeds.

Staphylococcus spp. abundance in milk was measured at three-time points during the first lactation by a qPCRbased technique developed at the "Interactions Hôtes - Agents Pathogènes" (IHAP) laboratory (Toulouse, France). Briefly, milk was collected aseptically from each half udder independently after precleaning and disinfecting the teat apex using a cotton wool moistened with $70 \%$ alcohol. Whole milk was centrifuged $(6000 g ; 20 \mathrm{~min})$ before two consecutive enzymatic proteolytic treatments with lysozyme and proteinase K. DNA was extracted using a Biosprint 96 semi-robotic workstation and DNA Blood kits (QIAGEN), and finally eluted in $50 \mu \mathrm{L}$ of distilled water. An internal DNA control (QIAGEN) was used to assess recovery and lack of qPCR inhibitors. High-throughput qPCR in 384-well format was performed on $1 \mu \mathrm{L}$ of DNA extract in a total volume of $5 \mu \mathrm{L}$ using tuf-specific primers (tuf 5'-CAC GAC CAG TGA TTG AGA ATA CG and tuf 3 '-CCA ATG CCA CAA ACT CGT GA), probe (CCA TTC ATG ATG CCA GTT G), and the Quantifast Pathogen PCR kit (QIAGEN). The proportion of inhibited samples was lower than $5 \%$. Values above the cycle threshold were compared to a standard curve obtained from known amounts of genomic DNA from a Staphylococcus aureus laboratory strain and expressed as a bacterial titre (quantity of equivalent bacterial genomes per volume of milk), on a logarithmic scale. The three results were averaged for each ewe and corrected for the effects of month and year of sampling (STAPH_L1).

Chronic mastitis was based on the presence of mammary abscesses, recorded by clinical examination (ABSCESS_L1). Animals were noted as "1" (case) when the presence of at least one abscess was detected at least twice, whereas animals were noted as "0" (control) when they were found to be healthy (without any abscess) at least three times during the first lactation.

Each ewe was weighed at birth (W_BIRTH), at 100 days (W_DAY_100) and 250 days (W_DAY_250), after the first (on average 412 days, W_1ST_LAMB) and second lambing (on average 744 days, W_2ND_LAMB), and at the age of 920 days (W_DAY_920). Phenotypes were corrected for year and feeding method (breastfeeding or artificial suckling). Basic statistics are in Table 1.

In the Manech Tête Rousse population, SCC and milk production traits were obtained from the official milk records. In this breed, milk yield is measured monthly and SCC, fat and protein contents are measured three to four times during the first three lactations [8]. For association mapping, we used the daughter yield deviations (DYD) [9] from regular national genetic evaluations for milk production traits (MILK, PROTEIN, and FAT) and lactation average somatic cell scores (LSCS). DYD correspond to the average performance of the daughters of a ram, corrected for the environmental effects and the genetic value of the dams (Table 2).

Both Lacaune and Manech Tête Rousse populations were genotyped with a 960 custom-designed ovine SNP chip [10]. The chip was designed and developed within the 3SR EU project [3] based on several QTL for SCC that were previously identified in Spanish Churra [11], French Lacaune [4] and Italian Sardinian-Lacaune backcross populations ([12] and personal 
Table 1 Number of animals with a phenotype (N) and basic statistics for the Lacaune population of 504 ewes

\begin{tabular}{lll}
\hline Trait & N & Mean $( \pm$ SD) \\
\hline LSCS_L1 & 494 & $3.1 \pm 1.6$ \\
FAT_L1 (g/L) & 494 & $64.1 \pm 7.1$ \\
PROTEIN_L1 (g/L) & 494 & $53.5 \pm 3.4$ \\
MILK_L1 ${ }^{\text {a }(L)}$ & 493 & $334.9 \pm 61.9$ \\
STAPH_L1 & 404 & $0.7 \pm 0.8$ \\
ABSCESS_L1 & 376 & 15 cases/361 controls \\
W_BIRTH (kg) & 502 & $3.9 \pm 0.6$ \\
W_DAY_100 (kg) & 492 & $28.7 \pm 3.0$ \\
W_DAY_250 (kg) & 472 & $50.6 \pm 4.1$ \\
W_1ST_LAMB (kg) & 438 & $64.7 \pm 6.7$ \\
W_2ND_LAMB (kg) & 393 & $73.4 \pm 7.7$ \\
W_DAY_920 (kg) & 378 & $67.3 \pm 7.2$ \\
\hline
\end{tabular}

${ }^{a}$ MILK_L1 is the 250-day cumulative production adjusted for lactation length and standardized to an adult production $(\times 1.3)$

Table 2 Number of animals with a phenotype (N) and basic statistics for the Manech Tête Rousse population of 145 rams and their 15,722 offspring

\begin{tabular}{|c|c|c|c|c|}
\hline \multirow[t]{2}{*}{ Trait } & \multicolumn{2}{|c|}{$\operatorname{Rams}^{\mathrm{a}}$} & \multicolumn{2}{|c|}{ Offspring ewes ${ }^{\mathbf{b}}$} \\
\hline & $\mathbf{N}$ & Mean $( \pm S D)$ & $\mathbf{N}$ & Mean $( \pm S D)$ \\
\hline LSCS & 145 & $0.1 \pm 0.6$ & 15,115 & $3.6 \pm 1.5$ \\
\hline FAT (g/L) & 145 & $0.9 \pm 4.2$ & 15,368 & $61.9 \pm 8.4$ \\
\hline PROTEIN (g/L) & 145 & $0.2 \pm 2.6$ & 15,368 & $49.3 \pm 4.4$ \\
\hline $\operatorname{MILK}^{\mathrm{C}}(\mathrm{L})$ & 145 & $84.7 \pm 25.2$ & 15,722 & $270 \pm 79$ \\
\hline
\end{tabular}

${ }^{a}$ Phenotypes are DYD expressed as deviations from the average population used for genetic evaluation

${ }^{b}$ Phenotypes are the observed performances during the first lactation

c MILK is the 250-day cumulative production adjusted for lactation length and standardized to an adult production $(\times 1.3)$

communication). Using these previous association studies, seven regions of interest (Table 3 ) on Ovis aries (OAR) chromosomes 2, 3, 5, 16 and 18 were selected based on commonalities among populations found at the time (in 2012) or on their high significance. SNPs were selected within these regions from the $54 \mathrm{~K}$ or $800 \mathrm{~K}$ Illumina ovine chips [13] or from novel genome sequencing within the 3SR project. The 10 SNPs in the OAR3 region included the causal mutation in the SOCS2 gene and nine other closely linked loci that had been identified by Rupp et al. [4]. Genomic positions refer to the ovine reference genome v3.1 [14]. After quality control, the following SNPs were excluded from the analyses: non-polymorphic SNPs, SNPs with a missingness rate higher than $5 \%$, with a minor allele frequency lower than $2 \%$, and SNPs that deviated from
Hardy-Weinberg proportion ( $p<1 \mathrm{E}-05)$, thus, 745 and 708 SNPs were selected for the Lacaune and Manech Tête Rousse populations, respectively.

Genome-wide association studies (GWAS) were performed for each phenotype using the polygenic univariate mixed model approach implemented in the genome-wide efficient mixed-model association (GEMMA) software [15]. The polygenic effect was fitted using a covariance structure according to the genomic relationship matrix. Corrections were applied to account for multiple testing. First, a Bonferroni correction of $\alpha=5 \%$ was applied (significance threshold $=\alpha$ /number of SNPs). SNPs with a $p$ value less than $6.6 \mathrm{E}-05$ and less than $7.1 \mathrm{E}-05$ were considered as highly significantly associated for the Lacaune and the Manech Tête Rousse populations, respectively. Since association tests are not independent, due to the large number of SNPs in high linkage disequilibrium within the QTL regions, and to several traits being highly correlated, a less restrictive suggestive significance threshold was also calculated (significance threshold $=[\alpha /$ number of independent regions in the chip $] /$ number of independent variables in the study). Table 3 lists the seven independent regions that were found to contain such SNPs on the 960 custom-designed ovine SNP chip. We used two methods to obtain the number of independent variables: a factor analysis of mixed data (FAMD) for the Lacaune population, for which we had to consider quantitative (LSCS_L1, FAT_L1, PROTEIN_ L1, MILK_L1, STAPH_L1, weights) and qualitative (ABSCESS_L1) phenotypes, and a principal component analysis (PCA) for the Manech Tête Rousse population, for which all phenotypes were quantitative. FAMD and PCA using phenotypes were computed using the FactoMineR package [16] of the R software [17]. According to the clustering elbow method, the number of independent variables is the marginal point where the percentage of variance explained by the PCA dimensions drops and produces an angle in the histogram. This method led us to choose the first five dimensions of the FAMD (Lacaune) and the first two dimensions of the PCA (Manech Tête Rousse), which explained 77.5\% (Lacaune) and 79.6\% (Manech Tête Rousse) of the variance. Therefore, we used N1 $=5$ (Lacaune) and N2 $=2$ (Manech Tête Rousse), the number of independent variables in the study, leading to suggestive significance thresholds of $1.4 \mathrm{E}-03$ and $3.6 \mathrm{E}-03$, respectively.

\section{Results and discussion}

Significant SNPs from the GWAS are in Table 4 (Lacaune) and Table 5 (Manech Tête Rousse). The first noteworthy result concerns the highly significant region on OAR3 in the Lacaune population. Indeed, three SNPs, which were associated with mastitis and growth traits, 
Table 3 SNPs of the 3SR-mastitis-960-SNP custom chip, selected within the 3SR EU project for their association with mastitis-related traits

\begin{tabular}{|c|c|c|c|c|c|c|c|c|c|c|}
\hline \multirow[t]{2}{*}{ OAR } & \multirow{2}{*}{$\begin{array}{l}\text { Discovery } \\
\text { population }\end{array}$} & \multirow[t]{2}{*}{$\mathrm{QTL}^{\mathrm{a}}(\mathrm{Mb})$} & \multicolumn{2}{|c|}{ Interval (Mb) } & \multicolumn{3}{|c|}{ Origin of the SNP } & \multicolumn{3}{|c|}{ Number of SNPs } \\
\hline & & & Start & End & $54 \mathrm{~K}$ chip & 800 K chip & SEQ & Before QC & After QC LAC & After QC MTR \\
\hline 2 & LAC & 125 & 124.6 & 125.5 & 19 & 10 & & 29 & 24 & 24 \\
\hline \multirow[t]{2}{*}{2} & SAR & 206.7 & 204.2 & 209.7 & 106 & 146 & & 252 & 196 & 180 \\
\hline & $\mathrm{CHU}$ & 208.7 & & & & & & & & \\
\hline 3 & LAC & 129.7 & 129.7 & 130.1 & 4 & 6 & 10 & 20 & 13 & 12 \\
\hline 5 & LAC & 96.5 & 95.8 & 96.2 & 11 & 9 & & 20 & 17 & 16 \\
\hline \multirow[t]{2}{*}{12} & $\mathrm{CHU}$ & 18.3 & 17.9 & 20.4 & 54 & 76 & & 130 & 101 & 97 \\
\hline & SAR & 18.4 & & & & & & & & \\
\hline 16 & LAC & 36.2 & 28.3 & 36.8 & 144 & 110 & & 254 & 202 & 183 \\
\hline \multirow[t]{2}{*}{19} & $\mathrm{CHU}$ & 26.3 & 23.6 & 28.9 & 75 & 180 & & 255 & 202 & 196 \\
\hline & LAC & 28.6 & & & & & & & & \\
\hline
\end{tabular}

OAR Ovis aries chromosome, LAC Lacaune, SAR Sardinian-Lacaune backcross, CHU Churra, QTL quantitative trait locus, Mb megabase, SEQ sequence, QC quality control, MTR Manech Tête Rousse

a QTL location

Table 4 List of SNPs associated with the different phenotypes for the Lacaune population genotyped with the 3SR-mastitis-960-SNP custom chip

\begin{tabular}{|c|c|c|c|c|c|c|c|c|}
\hline OAR & SNP ID & SNP position & MAF \% & $\begin{array}{l}\text { Estimation } \\
\text { of SNP effect }\end{array}$ & SE & $p$ value of Wald test & Significant & Trait \\
\hline \multirow[t]{6}{*}{2} & rs414463145 & 204256340 & 23 & -2.1 & 0.6 & $1.1 \mathrm{E}-03$ & & FAT_L1 \\
\hline & rs420100221 & 204333224 & 32 & -2.0 & 0.6 & $6.9 \mathrm{E}-04$ & & FAT_L1 \\
\hline & rs409223720 & 206118959 & 46 & 0.0 & 0.0 & $1.3 \mathrm{E}-03$ & & ABSCESS_L1 \\
\hline & rs406554330 & 206311785 & 35 & 0.1 & 0.0 & $8.2 \mathrm{E}-04$ & & ABSCESS_L1 \\
\hline & rs421656393 & 207088920 & 34 & 2.0 & 0.6 & $1.2 \mathrm{E}-03$ & & FAT_L1 \\
\hline & rs409595486 & 209135680 & 12 & 2.6 & 0.8 & $7.6 \mathrm{E}-04$ & & FAT_L1 \\
\hline \multirow[t]{13}{*}{3} & rs428428896 & 129680367 & 22 & 0.6 & 0.1 & $9.6 E-06$ & $* * *$ & LSCS_L1 \\
\hline & & & 22 & 0.3 & 0.1 & $1.4 \mathrm{E}-03$ & & STAPH_L1 \\
\hline & & & 21 & 2.0 & 0.6 & $1.1 \mathrm{E}-03$ & & W_1ST_LAMB \\
\hline & rs425616833 & 129685397 & 39 & -0.4 & 0.1 & $3.2 \mathrm{E}-04$ & & LSCS_L1 \\
\hline & rs868996547 & 129722200 & 17 & 0.8 & 0.1 & $3.0 E-07$ & $* * *$ & LSCS_L1 \\
\hline & & & 17 & 0.3 & 0.1 & $6.8 \mathrm{E}-04$ & & STAPH_L1 \\
\hline & & & 17 & 1.0 & 0.3 & $6.0 \mathrm{E}-04$ & & W_DAY_100 \\
\hline & & & 17 & 1.5 & 0.4 & 3.7E-04 & & W_DAY_250 \\
\hline & & & 16 & 2.4 & 0.7 & $5.0 \mathrm{E}-04$ & & W_1ST_LAMB \\
\hline & & & 15 & 2.8 & 0.9 & $9.5 E-04$ & & W_DAY_920 \\
\hline & rs426941860 & 129927538 & 20 & 0.7 & 0.1 & $5.2 E-07$ & $* * *$ & LSCS_L1 \\
\hline & & & 20 & 0.8 & 0.3 & $1.2 \mathrm{E}-03$ & & W_DAY_100 \\
\hline & & & 19 & 2.4 & 0.7 & $1.0 \mathrm{E}-03$ & & W_DAY_920 \\
\hline \multirow[t]{4}{*}{16} & rs404369966 & 28321220 & 25 & -0.2 & 0.0 & $3.2 E-04$ & & W_BIRTH \\
\hline & rs403769730 & 35801129 & 6 & 34.5 & 8.4 & $5.2 E-05$ & $* * *$ & MILK_L1 \\
\hline & & & 6 & 1.5 & 0.4 & $3.4 \mathrm{E}-04$ & & W_DAY_100 \\
\hline & & & 7 & 2.1 & 0.6 & $6.8 \mathrm{E}-04$ & & W_DAY_250 \\
\hline \multirow[t]{3}{*}{19} & rs412825949 & 25639818 & 32 & -0.3 & 0.1 & $4.1 \mathrm{E}-04$ & & STAPH_L1 \\
\hline & rs416350585 & 25684229 & 14 & 3.6 & 0.9 & $3.4 E-05$ & $* * *$ & W_DAY_920 \\
\hline & rs400011699 & 28086791 & 38 & -14.9 & 4.0 & $2.6 \mathrm{E}-04$ & & MILK_L1 \\
\hline
\end{tabular}

SNPs in italic are significant with the Bonferroni threshold and the others are significant with the suggestive threshold

OAR Ovis aries chromosome, MAF minor allele frequency, SE standard error of the estimated SNP effect 
Table 5 List of SNPs associated with the different phenotypes for the Manech Tête Rousse population genotyped with the 3SR-mastitis-960-SNP custom chip

\begin{tabular}{|c|c|c|c|c|c|c|c|}
\hline OAR & SNP ID & SNP position & MAF $\%$ & $\begin{array}{l}\text { Estimation of SNP } \\
\text { effect }\end{array}$ & SE & $p$ value of Wald test & Trait \\
\hline \multirow[t]{4}{*}{2} & rs403180214 & 206231638 & 50 & -0.3 & 0.1 & $1.7 \mathrm{E}-04$ & LSCS \\
\hline & rs430641657 & 207218842 & 12 & 16.0 & 4.3 & $2.9 \mathrm{E}-04$ & MILK \\
\hline & rs425558509 & 208650955 & 42 & -1.5 & 0.5 & $2.6 \mathrm{E}-03$ & FAT \\
\hline & rs398918249 & 209409342 & 43 & -1.0 & 0.3 & $1.3 \mathrm{E}-03$ & PROTEIN \\
\hline \multirow[t]{13}{*}{16} & rs404369966 & 28321220 & 26 & 1.0 & 0.3 & $3.6 \mathrm{E}-03$ & PROTEIN \\
\hline & & & 26 & -10.2 & 3.4 & $2.7 \mathrm{E}-03$ & MILK \\
\hline & rs428277629 & 28526130 & 35 & 1.0 & 0.3 & $2.0 \mathrm{E}-03$ & PROTEIN \\
\hline & rs418639132 & 28632456 & 41 & 1.0 & 0.3 & $1.0 \mathrm{E}-03$ & PROTEIN \\
\hline & rs405638287 & 29030021 & 37 & 1.1 & 0.3 & $7.4 \mathrm{E}-04$ & PROTEIN \\
\hline & rs399031726 & 29072599 & 36 & 1.2 & 0.3 & $2.5 \mathrm{E}-04$ & PROTEIN \\
\hline & rs422927329 & 29304504 & 37 & 1.2 & 0.3 & $1.1 \mathrm{E}-04$ & PROTEIN \\
\hline & rs402269497 & 30319608 & 19 & -12.5 & 3.8 & $1.2 \mathrm{E}-03$ & MILK \\
\hline & rs421638047 & 30692759 & 28 & 1.9 & 0.6 & $1.1 \mathrm{E}-03$ & FAT \\
\hline & & & 28 & 1.2 & 0.3 & $6.1 \mathrm{E}-04$ & PROTEIN \\
\hline & & & 28 & -12.9 & 3.4 & $2.1 \mathrm{E}-04$ & MILK \\
\hline & rs409981325 & 31298560 & 10 & 0.4 & 0.1 & $1.9 \mathrm{E}-03$ & LSCS \\
\hline & rs409954614 & 34424863 & 37 & 1.0 & 0.3 & $1.2 \mathrm{E}-03$ & PROTEIN \\
\hline
\end{tabular}

There are no significant SNPs at the Bonferroni threshold for this breed, all the SNPs presented in this table are significant with the suggestive threshold OAR Ovis aries chromosome number, MAF minor allele frequency, SE standard error of the estimated SNP effect

were detected at the Bonferroni threshold. The most significant SNP ( $r s 868996547, p$ value $=3.0 \mathrm{E}-07$ ) was the causal mutation in the SOCS2 gene, previously reported by Rupp et al. [4]. This mutation causes a loss in functional activity of the SOCS2 protein, which is involved in inflammatory response control and growth [18] through the JAK/STAT/SOCS pathway. The lowest $p$ values and highest estimates of effects for this SNP were observed for both mastitis traits (LSCS_L1 and STAPH_L1) and four of the six weight traits. Corresponding effects varied from 0.33 SD for W_DAY_100 to 0.50 SD for LSCS_L1. Thus, we confirmed an adverse effect of the SOCS2 gene point mutation on mammary inflammation and growth, as reported by Rupp et al. [4]. We also found that the mutation had an unfavourable effect on the infectious status of the udder (0.38 SD), since the low-frequency allele increased cell counts and bacteria shedding in milk. All these results confirm the pleiotropic effect of the SOCS2 mutation on body growth and the host's control of mastitis. This SNP did not segregate in the Manech Tête Rousse population although 12 other SNPs segregated in this narrow genomic region (Table 3). No QTL for mastitis was detected in this region for the Manech Tête Rousse population (Table 5), which provides further evidence that $r s 868996547$ is a strong candidate in Lacaune but is absent from Manech Tête Rousse. Moreover, we found that there was no effect of the SNPs of the same region on OAR3 when the SNP considered as causal ( $r$ 868996547) was included as a fixed factor in the model for the Lacaune population analyses. Indeed, we observed an increase of the $p$ values of the SNPs that surround the mutation for all traits for which the association was previously significant. For example, the minimum $p$ value for the LSCS_L1 trait in the OAR3 region was 1.5E-02 (rs425616833), which confirmed that the other SNPs in the region do not explain any additional variance.

Then, we applied suggestive thresholds, which allowed us to confirm three other regions that are associated with mastitis. In the Lacaune population, regions on OAR2 and 19 are associated with the ABSCESS_L1 and STAPH_L1 traits, respectively, and regions on OAR2 and 16 are also significant for the LSCS trait in the Manech Tête Rousse population. For significant SNPs, the effect varied from 0.38 SD (OAR19 in Lacaune) to 0.67 SD (OAR16 in Manech Tête Rousse) of the traits (Tables 4, 5). These three QTL regions had already been identified in Sarda (OAR2), Churra (OAR19 and 2) (Table 3) and Chios breeds (OAR2, 16 and 19) [5]. Thus, for these regions, and especially OAR2, our data reinforce the hypothesis of true mastitis QTL, which might involve similar genes and pathways across breeds. Banos et al. [5] suggested several candidate genes for OAR2: cytotoxic T-lymphocyte-associated protein 4 (CTLA42; 
204,777,523-204,784,522 bp), inducible T-cell co-stimulator (ICOS; 204,851,429-204,873,693 bp), and isocitrate dehydrogenase 1 (NADP+), soluble (IDH1; 209,236,699209,259,307 bp), which are involved in T-cell responses or mitigation of oxidative damage. However, the region between 204.2 and 209.7 Mbp on OAR2 includes more than 90 genes, which makes the identification of appropriate candidates difficult.

Interestingly, two of the mastitis QTL regions (OAR2 and 16) that were confirmed in the present study, were also associated with milk production traits in both populations. Moreover, the region on OAR16 is strongly (Bonferroni threshold) associated with MILK_L1 (effect $=0.56$ $\mathrm{SD}$ ) in the Lacaune population and with MILK, FAT, and PROTEIN (effect $=0.50$ SD, $0.45 \mathrm{SD}$ and $0.46 \mathrm{SD}$, respectively) in the Manech Tête Rousse population. Thus, the underlying QTL could be a QTL for milk production that has an indirect impact on mastitis. In Lacaune, the positive sign of the estimated effects of SNP rs403769730 shows that this QTL is favourable for milk production (Table 4), i.e. leading to an increase in milk quantity, but unfavourable for LSCS_L1 (results not shown), i.e. leading to an increase in somatic cell count. A similar pattern is observed for SNP rs421638047 in Manech Tête Rousse, for which the estimated effects have a negative sign, i.e. leading to a decrease in MILK which is unfavourable for milk yield (Table 5) and a decrease in LSCS which is favourable for the health of the animal (results not shown). These results are in agreement with the positive and antagonistic correlation that exists between mastitis and milk production trait in Lacaune [19] and other ovine [20] and bovine breeds [21], which indicates, at least in part, a genomic basis for the trade-off between milk production and mastitis resistance.

\section{Conclusions}

We confirmed four out of seven QTL regions for mastitis in the Lacaune population, and only two in the Manech Tête Rousse population. This is consistent with the fact that Lacaune belongs to the breeds for which these regions were first discovered, although the individuals were different. The two significant regions detected in the Manech Tête Rousse population are rather encouraging, unlike a similar study on nematode resistance where QTL validation was inconclusive [22]. These results demonstrate that mastitis-related genetic mechanisms are shared between different distant dairy sheep populations.

\section{Authors' contributions}

CO performed the association analyses, contributed to their interpretation and wrote the draft. CA and DP conducted the experiment at the facility of La Fage, collected and prepared the data from the Lacaune population. GF developed and carried out the measurements of PCR-based milk bacteriology in the Lacaune population. He also led the REIDSOCS ANR funded project. AS, GTK and RR developed the 3SR-mastitis-960-SNP chip. JMA contributed to data collection and performed phenotype calculations in the Manech Tête Rousse population. JS conducted the DNA extractions. GTK and RR designed the study and helped to interpret the analyses. All authors read and approved the final manuscript.

\section{Author details}

${ }^{1}$ GenPhySE, Université de Toulouse, INRA, ENVT, Castanet-Tolosan, France. ${ }^{2}$ INRA, Domaine de La Fage, 12250 Saint-Jean-et-Saint-Paul, France. ${ }^{3}$ IHAP, Université de Toulouse, INRA, ENVT, Castanet-Tolosan, France. ${ }^{4}$ Parco Tecnologico Padano (PTP), Via Einstein, Cascina Codazza, 26900 Lodi, Italy. ${ }^{5}$ Institut de l'Elevage, 31321 Castanet-Tolosan, France.

\section{Acknowledgements}

The authors are grateful to Francis Fidelle (CDEO, Ordiarp, France) and the technical staff of La Fage (INRA, France) for assisting with animal care and data collection. We thank Edinburgh Genomics (formerly ARK Genomics platform) for genotyping the 960-SNP chip. Thanks are also extended to Julie Demars (INRA Toulouse, France) for her help in handling blood and DNA samples, and Christian Tasca for preparing milk samples for bacteriology by qPCR. The work was funded by the 7PCRD EU 3SR project (Sustainable Solutions for Small Ruminants, FP7-KBBE-245140). Claire Oget acknowledges the support of the Agence Nationale de la Recherche (ANR) for her scholarship (Project Reidsocs, ID: ANR-16-CE20-0010).

\section{Competing interests}

The authors declare that they have no competing interests.

\section{Availability of data and materials}

Information about the 960 custom-designed ovine SNP chip that was developed within WP3 of the 3SR program and used for the analyses in the current study is available online: http://genoweb.toulouse.inra.fr/ tosser/3SRWP3-960_snp_mastitis/. The datasets used and analysed during the current study are available from the corresponding author on reasonable request.

\section{Consent for publication}

Not applicable.

\section{Ethics approval and consent to participate}

The commercial rams from the Manech Tête Rousse population did not belong to any experimental design but were sampled by veterinarians and/or under veterinarian supervision for routine veterinary care and DNA collection. For the experimental animals (INRA, Domaine de La Fage), breeding conditions were similar to those of commercial sheep flocks. Blood collection and measurements followed procedures approved by the Regional Ethics Committee on Animal Experimentation, Occitanie (France), under the Agreement 752056/00.

\section{Funding}

This work was supported by grants from the EU 3SR project (FP7-KBBE, Project ID: 245140) and the French National Research Agency (ANR) REIDSOCS project (ANR 2016, Project ID: ANR-16-CE20-0010).

\section{Publisher's Note}

Springer Nature remains neutral with regard to jurisdictional claims in published maps and institutional affiliations.

Received: 20 September 2018 Accepted: 1 February 2019

Published online: 13 February 2019

\section{References}

1. Bergonier D, de Crémoux R, Rupp R, Lagriffoul G, Berthelot X. Mastitis of dairy small ruminants. Vet Res. 2003;34:689-716.

2. Rupp R, Foucras G. Genetics of mastitis in dairy ruminants. In: Bishop SC, Axford RFE, Nicholas FW, Owen JB, editors. Breeding for disease resistance in farm animals. 3rd ed. Wallingford: CABl; 2010. p. 183-212.

3. Sustainable solutions for small ruminants. Projects FP7-KBBE European Commission. CORDIS European Commission. https://cordis.europa.eu/ project/rcn/95054_en.html. Accessed 17 May 2018. 
4. Rupp R, Senin P, Sarry J, Allain C, Tasca C, Ligat L, et al. A point mutation in suppressor of cytokine signalling 2 (Socs2) increases the susceptibility to inflammation of the mammary gland while associated with higher body weight and size and higher milk production in a sheep model. PLoS Genet. 2015;11:e1005629.

5. Banos G, Bramis G, Bush SJ, Clark EL, McCulloch MEB, Smith J, et al. The genomic architecture of mastitis resistance in dairy sheep. BMC Genomics. 2017; 18:624

6. Rupp R, Bergonier D, Dion S, Hygoneng MC, Aurel MR, Robert-Granié $C$, et al. Response to somatic cell count-based selection for mastitis resistance in a divergent selection experiment in sheep. J Dairy Sci. 2009;92:1203-19.

7. Ali AKA, Shook GE. An optimum transformation for somatic cell concentration in milk. J Dairy Sci. 1980;63:487-90.

8. Barillet F, Astruc JM, Lagriffoul G, Aguerre X, Bonaïti B:: Selecting milk composition and mastitis resistance by using a part lactation sampling design in French Manech red faced dairy sheep breed. In: Proceedings of the 36th ICAR biennial session: 16-20 June 2008. Niagara Falls; 2009. p. 129-35. https://www.cabdirect.org/cabdirect/abstract/20103193070. Accessed 3 Apr 2018.

9. VanRaden PM, Wiggans GR. Derivation, calculation, and use of national animal model information. J Dairy Sci. 1991;74:2737-46.

10. Index of/ tosser/3SR-WP3-960_snp_mastitis. http://genoweb.toulouse. inra.fr/ tosser/3SR-WP3-960_snp_mastitis/. Accessed 17 May 2018.

11. Gutiérrez-Gil B, Esteban-Blanco C, Suarez-Vega A, Arranz JJ. Detection of quantitative trait loci and putative causal variants affecting somatic cell score in dairy sheep by using a $50 \mathrm{~K}$ SNP-chip and whole-genome sequencing. J Dairy Sci. 2018;101:9072-88.

12. Sechi S, Casu S, Casula M, Congiu GB, Miari S, Mulas G, et al. Genomewide association analysis of resistance to paratuberculosis and mastitis in dairy sheep. In: Proceedings of the 64th annual meeting of the European federation of animal science: 26-30 August 2013. Nantes; 2013. http:// old.eaap.org/Previous_Annual_Meetings/2013Nantes/Papers/Published/ S54_06.pdf. Accessed 17 May 2018.

13. Nicolazzi EL, Caprera A, Nazzicari N, Cozzi P, Strozzi F, Lawley C, et al. SNPchiMp v.3: integrating and standardizing single nucleotide polymorphism data for livestock species. BMC Genomics. 2015;16:283.

14. Ovis aries - Ensembl genome browser 92. http://www.ensembl.org/ Ovis aries/Info/Index. Accessed 17 May 2018.

15. Zhou X, Stephens M. Genome-wide efficient mixed-model analysis for association studies. Nat Genet. 2012;44:821-4.

16. Lê S, Josse J, Husson F. FactoMineR: an R package for multivariate analysis. J Stat Softw. 2008;25:1-18.

17. R Development Core Team. R: A language and environment for statistical computing. 2005. http://www.R-project.org/. Accessed 1 Jun 2018.

18. Metcalf D, Greenhalgh CJ, Viney E, Willson TA, Starr R, Nicola NA, et al. Gigantism in mice lacking suppressor of cytokine signalling-2. Nature. 2000;405:1069-73.

19. Rupp R, Lagriffoul G, Astruc JM, Barillet F. Genetic parameters for milk somatic cell scores and relationships with production traits in French Lacaune dairy sheep. J Dairy Sci. 2003;86:1476-81.

20. Tolone M, Riggio V, Portolano B. Estimation of genetic and phenotypic parameters for bacteriological status of the udder, somatic cell score, and milk yield in dairy sheep using a threshold animal model. Livest Sci. 2013;151:134-9.

21. Rupp R, Boichard D. Genetics of resistance to mastitis in dairy cattle. Vet Res. 2003;34:671-88.

22. Keane OM, Hanrahan JP, McRae KM, Good B. An independent validation study of loci associated with nematode resistance in sheep. Anim Genet. 2018;49:265-8.
Ready to submit your research? Choose BMC and benefit from:

- fast, convenient online submission

- thorough peer review by experienced researchers in your field

- rapid publication on acceptance

- support for research data, including large and complex data types

- gold Open Access which fosters wider collaboration and increased citations

- maximum visibility for your research: over 100M website views per year

At $\mathrm{BMC}$, research is always in progress.

Learn more biomedcentral.com/submissions 